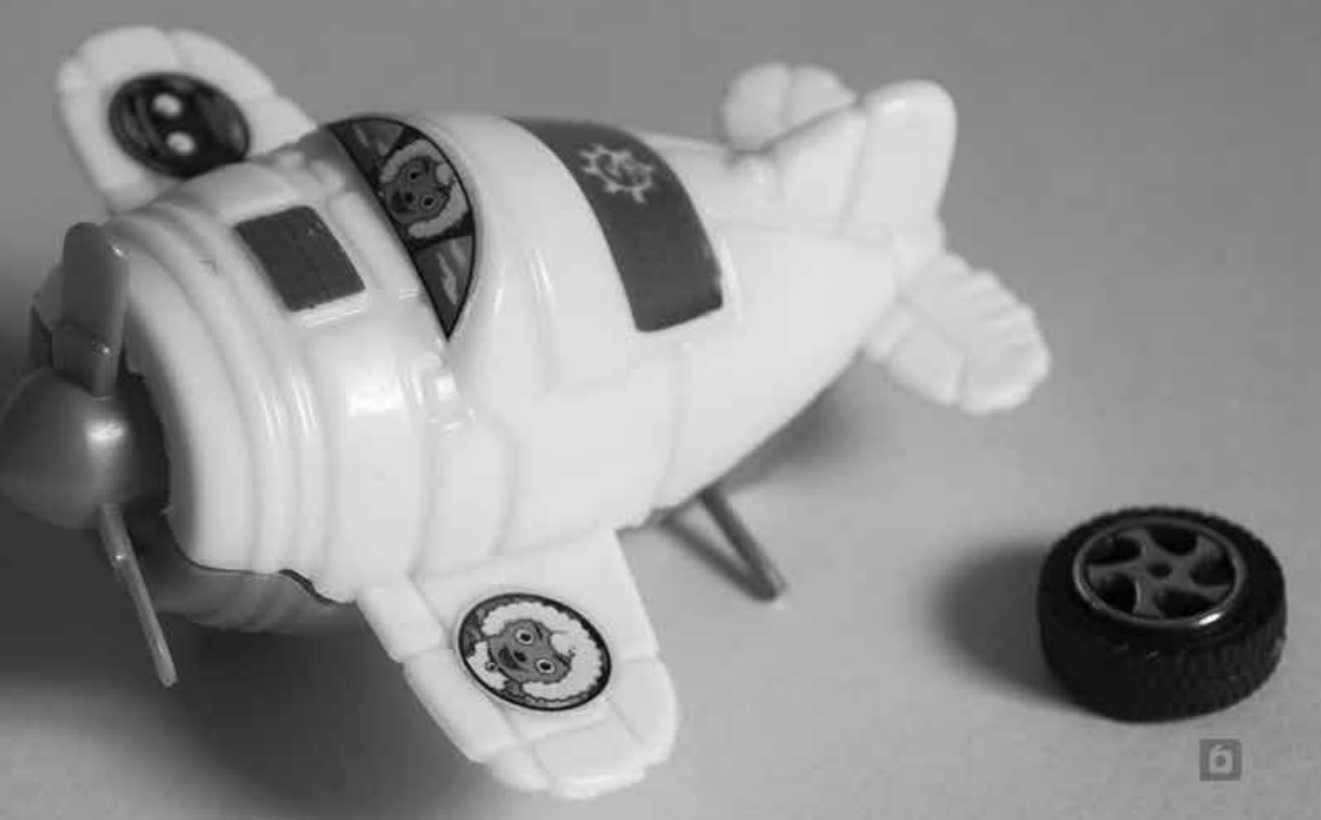

\title{
Tránsito de la educación especial a la educación inclusiva: sendas diferenciadas en el entorno educativo
}

Transit of special education to the inclusive education: paths differentiated in the educational environment

Trânsito da educação especial à educação inclusiva: sendas diferenciadas no meio educativo 


\section{Diana Patricia García Ríos María del Socorro Jutinico Fernández}

1 Profesora de planta de la Universidad Distrital Francisco José de Caldas. Facultad de Ciencias y Educación. Magister en Educación con énfasis en comunitaria; correo electrónico:dianapatriciasecret@gmail.com

2 Profesora de planta de la Universidad Distrital Francisco José de Caldas. Facultad de Ciencias y Educación. Magister en Desarrollo Educativo y Social, convenio Universidad Pedagógica Nacional y CINDE; correo electrónico: mdjutinicof@udistrital.edu.co

Fecha de recepción: 19 de diciembre de 2013 / Fecha de aprobación: 9 de mayo de 2014

\section{Resumen}

El objetivo de este trabajo es hacer un recorrido por las diferentes prácticas educativas que han marcado la educación de las personas llamadas diferentes o diversas, especialmente de aquellas en situación de discapacidad. El documento presenta una breve descripción del tránsito de la Educación Especial hacia la Educación Inclusiva, haciendo énfasis en esta última. Para finalizar, plantea algunas reflexiones propias de la formación docente a partir de una perspectiva de reconstrucción social, desde la cual el reto de la educación inclusiva puede ser posible.

\section{Palabras clave: Educación} Especial, integración, necesidades educativas especiales, educación inclusiva, formación de maestros.

\section{Summary}

This work has the objective to take a tour thoughout the different education practices that have emphsiezed the education of people so called different or diverse, especially since the people are in a disabily situation. The document presents a brief description of the transformation of Special Education to Inclusive Education with an emphasis on this last one. Finally, it suggest some own reflections of Teacher Education form a perspective of social reconstruction from which the challenge of Inclusive Education can be possible.

\section{Keywords: Special Educaction,} integration, Educaction Special Needs, Inclusive education, Teacher Training.

\section{Resumo}

O objetivo deste artigo é fazer um percurso por as diferentes praticas educacionais que têm marcado a educação de pessoas consideradas "diferentes" ou "diversas", especialmente as pessoas em situação de deficiência. O texto apresenta a breve descrição da passagem da Educação Especial para a Educação Inclusiva, com ênfase nesta última. Por fim, colocam-se algumas reflexões próprias sobre a formação de docentes na perspectiva da reconstrução social desde a qual o desafio da educação inclusiva seja possível.

\section{Palavras chave: Educação} Especial, Integração, Necessidades Educacionais Especiais, Educação Inclusiva, formação de mestres. 


\section{Algunos desarrollos teóricos sobre la Educación Especial}

— n Colombia y en el mundo, el concepto de discapacidad se configura como una temática de gran importancia que da pie a multitud de controversias y desencuentros en torno a los sentimientos y situaciones de exclusión, discriminación, tolerancia, aceptación o simplemente lástima que genera en nuestra sociedad; sentimientos y situaciones que están íntimamente ligados con las dinámicas sociales, educativas y legales que circulan en nuestra cotidianidad.

La historia ha demostrado que las concepciones de minusvalía, déficit e indefensión, entre otras, de la sociedad frente a la población con estas condiciones, han conducido a que se la invisibilice y se la reduzca a una categoría de ciudadanos de segunda que no están en condiciones de aportar el desarrollo de la sociedad. Esta imagen negativa, y si se quiere equivocada y prejuiciosa, que ha persistido sobre las personas en situación de discapacidad, ha traído como consecuencia la vulneración de casi todos sus derechos, y en particular la vulneración de su derecho a la educación, pues su acceso ha sido y es aún limitado. Pero el panorama no es tan desastroso, veamos cómo han evolucionado estas percepciones, para llegar a lo que hoy denominamos la inclusión educativa de esta población. Hacerlo significa comenzar por un breve recorrido histórico.

A pesar de que en las últimas décadas se han producido importantes transformaciones en las políticas respecto a la atención educativa de las personas con discapacidad, aún se presentan situaciones desfavorables que obstaculizan su vinculación a procesos de escolarización o reproducen esquemas de segregación que afectan negativamente, tanto a las personas con discapacidad, como a sus familias. A continuación se expondrán algunos rasgos generales que han caracterizado estas prácticas educativas.

La Educación Especial ha pasado por diferentes etapas de conceptualización. Inicia con una óptica de segregación pues consideraba a las personas como "limitadas", "deficientes", "anormales" o "subnormales", y eran ubicadas en centros especializados que funcionaban bajo una modalidad de atención clínico-asistencialista proveniente del campo de la Medicina. Se concebía a la persona con discapacidad como un "paciente" enfermo que debía ser rehabilitado por un especialista en un lugar apartado de la familia y de la sociedad en general, configurándose de esta manera como un factor de exclusión y discriminación.
Este ha sido el enfoque dominante de la educación especial, y fue caracterizado por Riddel (1998) y Echeita (2006) como una perspectiva esencialista. En este contexto, la visión de la educación especial sostiene que las dificultades del alumno son internas y causadas por su incapacidad o déficit; en tal sentido, tiende a sobrevalorar el papel del diagnóstico de tales déficits y se centra en su clasificación. La responsabilidad educativa para atender estas personas recae en un profesorado especial, liberando al profesorado regular de hacerlo. Con este tratamiento lo que se ha logrado es reforzar la segregación del alumnado a través de un sistema educativo especial paralelo al ordinario (Echeita, 2006, p. 31).

Algunos investigadores han manifestado que esta tendencia a diagnosticar y etiquetar a las personas de acuerdo con su deficiencia, ha producido un efecto negativo en su progreso escolar. Esto es cierto, porque calificar a un estudiante como deficiente y con dificultades para aprender, condiciona la expectativa del profesor frente a sus capacidades reales y lo induce a centrarse en aquello que no puede hacer, dejando de lado las demás características y capacidades de esa persona. Frente a esta situación, no es extraño que el profesor adecúe sus expectativas de progreso a la deficiencia o incapacidad del estudiante, limitando su intervención pedagógica a un solo aspecto, lo cual trae como consecuencia que el alumno progrese poco y, por consiguiente, se refuerce una imagen estereotipada de la persona como incapaz.

Una práctica pedagógica de estas características conduce a la reducción y el encasillamiento de las respuestas educativas, en el entendido de que la atención de una deficiencia requiere intervención específica, especializada y compensatoria. Echeita (2006, p. 35) afirma que esto ocurre por: “[...] la creencia generalizada de que los alumnos y alumnas especiales requerían métodos y estrategias de enseñanza igualmente especiales, que solo un profesorado particularmente preparado en ellas estaría en disposición de conocer y utilizar de forma adecuada".

Por considerar la intervención como algo especializado, la enseñanza se organiza en forma individualizada o por pequeños grupos separados de los demás estudiantes (considerados "normales"). Una práctica de esta naturaleza se configura como una situación de discriminación y exclusión, dado que priva a los niños de la posibilidad de relacionarse con sus pares, limitando sus oportunidades de interacción social y de trabajo colectivo, procesos que se consideran de vital importancia para potenciar el aprendizaje y el desarrollo de todo ser humano. 
Los planteamientos analizados hasta el momento permiten entrever que la perspectiva individual o esencialista ha funcionado no solo en detrimento de la formación y desarrollo de los estudiantes con discapacidad, sino que además ha reforzado la idea de la discapacidad como una desviación, condenando a estas personas a vivir en una situación de marginación y de desventaja. En otras palabras, y recurriendo a lo planteado por García Pastor $(1986,1993)$, se puede decir que la educación especial no está organizada desde la necesidad de progreso social, sino desde la búsqueda de eliminar los obstáculos a ese progreso.

Ante los pobres resultados alcanzados por este modelo, muchos autores y profesionales del ámbito de la educación se han dado a la tarea de tratar de re-significar y re-conceptualizar el objeto, el sentido y la finalidad de la educación especial. Este proceso, como veremos más adelante, se ha sustentado en la búsqueda de una educación de calidad para todos.

Según Echeita (2006), hay dos trabajos importantes que han influido, desde la década de los 80, en el sentido de impulsar la re-conceptualización de la educación especial: 1) El informe Warnok (DES, 1978, citado por Echeita), con la introducción y puesta en marcha del concepto de Necesidades Educativas Especiales, y con el avance hacia una perspectiva más contextual e interactiva de los procesos educativos que afectan el alumnado. 2) La Conferencia Mundial sobre Necesidades Educativas Especiales, acceso y calidad (UNESCO, 1994), celebrada en Salamanca, que apostó por una visión renovada de la educación especial hacia una perspectiva de educación inclusiva.

En síntesis, el informe Warnok plantea que todo niño con deficiencia es educable y que independientemente de su dificultad debe vincularse a la educación especial; además, rechaza la idea de clasificar los niños en dos grupos: deficientes y no deficientes, de los cuales los primeros reciben educación especial y los segundos simplemente educación; en contraposición a esto, propone entender la educación especial como un continuo de acciones que van, desde la ayuda temporal, hasta la adaptación permanente o a largo plazo del currículo ordinario. Se vislumbra entonces una mirada de la educación especial como un campo más complejo y flexible.

También cabe resaltar que el informe recomienda abolir la clasificación de los alumnos como deficientes y propone una descripción detallada de las necesidades especiales, esto como mecanismo para tomar decisiones acerca del proceso educativo de las personas con discapacidad; en este sentido, se acordó utilizar el término "dificultades de aprendizaje" de carácter leve, moderado o severo, términos que avanzaban hacia una perspectiva mucho más amplia e interactiva, en comparación con la tradicional concepción sobre las características particulares de los niños.

Echeita (2006, p. 40), utiliza la expresión "El efecto Warnok" para referirse a las propuestas y cambios acaecidos después de la publicación del informe, lo que le permite decir este "efecto" ha tenido varias consecuencias importantes:
"En primer lugar, tuvo el gran merito de transmitirnos una visión más optimista de la educación especial. Desde entonces hemos apren- dido que no debemos ser nosotros quienes a priori limitemos, con nuestras expectativas negativas, las posibilidades reales de aprendizaje de cualquier estudiante. Frente a la visión un tanto negativa del con- cepto de deficiencia, que tiende a resaltar lo que el alumno no puede hacer, o no tiene, y una visión de la educación especial como algo marginal y volcada más en el cuidado de sus alumnos. Estos análisis aportaban una visión más positiva y centrada en nuestro compromiso con las posibilidades de aprendizaje de todos los alumnos".

Indudablemente el informe Warnok sirvió no solo para impulsar en muchos países la política de integración escolar, sino para abrir el debate sobre el papel de la educación especial; también contribuyó en la comprensión de una trasformación que se venía dando, no solo como un cambio de lenguaje, sino conceptual, en correspondencia con las necesidades y características de los estudiantes, desde el reconocimiento de la heterogeneidad a partir de la situación de aprendizaje y no desde la condición definida por la naturaleza del desorden (Arnaiz, 2003).

De otra parte, cabe mencionar que en el contexto educativo circulan distintas posturas frente a la integración. Garrido (1993), analiza dichas posturas y presenta algunas que han tenido impacto y son vigentes actualmente. En unas se entiende la integración como la vinculación de un niño considerado "anormal" a una institución escolar, para que se relacione con otros denominados "normales". Otras, postulan como principio el derecho de toda persona a acceder a la educación sin ningún tipo de discriminación, intentando de esta manera eliminar la exclusión a la que están expuestos.

Aunque estas posturas se constituyen en un avance importante frente a la tradicional forma de conducir la educación especial, aún no han logrado rescatar de la marginación y la segregación a la población que atienden. Quizás esta situación obedece, entre otras razones, a la persistencia de unas prácticas centradas en la rotulación de los estudiantes y a la marcada insistencia en 

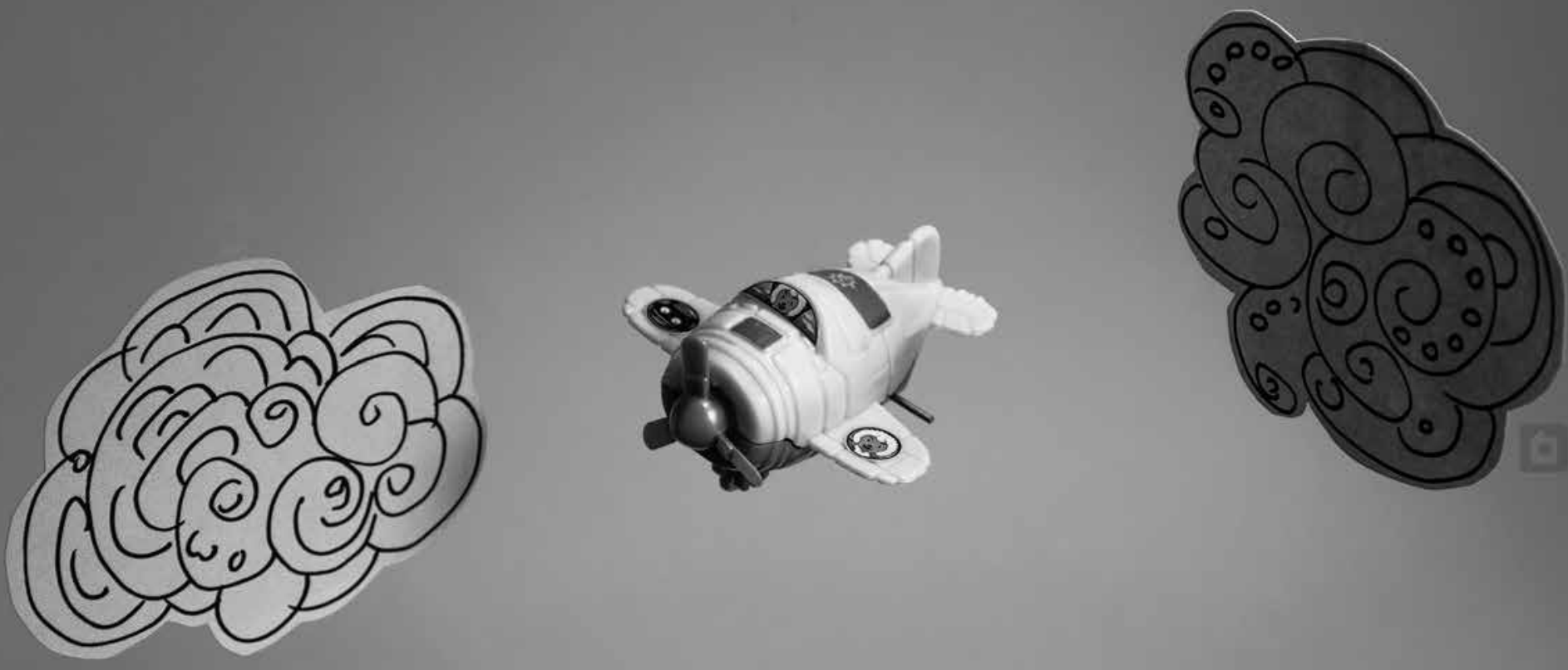

desarrollar el proceso educativo en un sentido homogenizante y normalizador, pretendiendo desaparecer la diferencia como elemento constitutivo del ser humano y propiciando así prácticas en las que se refleja el desconocimiento del otro. Bajo este horizonte, lo que se logra evidenciar es que desde la propuesta de integración, el estudiante es quien debe adaptarse a los requerimientos de la institución educativa, exigencia que desconoce sus necesidades y capacidades particulares.

En últimas, lo problemático de esta perspectiva es que el sistema educativo no cambió lo suficiente y se limitó a hablar de una simple integración física, de un estar ahí, pero sin participar y ser reconocido y valorado; como señala Parrillas (2002, p. 17, citado por Echeita, 2006, p. 83):

"[...] en esta fase de reformas integradoras, las políticas educativas que se mantienen sectorizadas por grupos de población comparten el reconocimiento de la igualdad ante la educación, pero limitando esa igualdad únicamente al acceso a la educación. En ningún modo se garantiza el derecho a recibir respuestas a las propias necesidades desde la igualdad $y$, mucho menos, la igualdad de metas $[\ldots]$ las reformas integradoras consisten más en un proceso de adición que de transformación profunda de las escuelas".

En pleno auge y desarrollo de la política de integración, en 1994 aparece una publicación: la declaración de Salamanca, que configura otras posibilidades de re-conceptualización de la educación especial. Este documento presenta algunas recomendaciones que evidencian un avance frente a lo planteado en el informe Warnok. Es así como se destacan particularmente cuatro:

- Una conceptualización más amplia y comprensiva del término Necesidades Educativas Especiales en relación con la población escolar, desde la cual se acuña una visión más interactiva y contextualizada respecto a las diferencias individuales y a la acción educativa que ellas comportan.

- En este sentido, la declaración de Salamanca dio respaldo al concepto de Necesidades Educativas Especiales, resaltando que cualquier estudiante puede presentar dificultades en su aprendizaje en un momento u otro de su experiencia educativa, sin que ello signifique, en palabras de Echeita (2006), que hay algo mal en él.

- La aclaración de que una educación que atiende la diversidad del estudiantado es la oportunidad para alcanzar la excelencia y la equidad educativa. En efecto, este aspecto se vislumbra como el eje central para la definición de políticas educativas y de estrategias para promover la integración de las personas con Necesidades Educativas Especiales.

- La recomendación de vincular los procesos de fortalecimiento educativo, de las personas con Necesidades Educativas Especiales, con acciones de reforma educativa en el sistema general. Este punto pone de manifiesto que no se trata de reformas puntuales, sino que se refiere a transformaciones que afecten la esencia misma del sistema educativo.

- La solicitud de que los programas de estudios deben ser revisados para adaptarlos a las necesidades de los niños y no al revés. Además, se da una demanda de que los profesores deben asumir la responsabilidad del progreso de todos sus estudiantes, incluidos los que experimentan algunas dificultades, en otras palabras, este asunto es responsabilidad del profesor del aula regular. Estos aspectos son muy importantes y resultan pertinentes, pero es claro que para alcanzar este propósito deben organizarse sistemas de apoyo a los docentes, para que puedan asumir la responsabilidad de todos los alumnos. 
Estas y otras directivas de la declaración de Salamanca, permiten recoger un número importante de razones y argumentos para promover un cambio de la educación especial hacia una perspectiva más educativa y sustentada en el principio de la educación para todos.

\section{La educación inclusiva, una perspectiva enmarcada en la educación para todos}

En todas las épocas los seres humanos han enfrentado una amplia gama de conflictos, los cuales en muchos momentos generan fracturas profundas en los grupos sociales, generando situaciones de exclusión y poniendo en peligro su cohesión. Son muchos los factores que inciden en el fenómeno de la exclusión social, entre ellos, la pobreza, la falta de oportunidades de participación, la no satisfacción de las necesidades humanas básicas y la falta de oportunidades para acceder a los beneficios de vivienda, educación, salud y empleo, entre otros. En tal sentido, la exclusión podría definirse como un:

"[...] proceso de apartamiento de los ámbitos sociales propios

de la comunidad en la que se vive, que conduce a una pérdida de

autonomía para conseguir los recursos necesarios para vivir, inte-

grarse y participar en la sociedad de la que se forma parte" (Vélaz de Medrano, 2002, p. 291, citado por Echeita, 2006).

Junto a estos procesos excluyentes habría que añadir la intolerancia en torno a lo étnico, religioso y cultural, que conduce incluso a generar graves situaciones de discriminación y violencia entre las comunidades. Frente a estos hechos, no es extraño entonces que la aspiración de la inclusión y su vinculación como práctica a los procesos educativos, surja como valor necesario para construir una cultura de paz y convivencia que permita a la humanidad reconciliarse con los valores perdidos.

Pero ocurre que el sistema educativo es una fuente de exclusión social y en sus distintos escenarios circulan mecanismos de segregación que terminan deteriorando la calidad de vida de sus integrantes. Echeita (2006) afirma que existen otras formas de exclusión que son encubiertas y que surgen a través de las barreras impuestas por el sistema escolar, limitando la participación o inhibiendo el aprendizaje de algunos alumnos. Barreras como las que experimentan quienes pertenecen a grupos minoritarios, también aquellos que aprenden a un ritmo más lento que los demás o quienes, por su género u orientación sexual, son víctimas de discriminación y rechazo.
A pesar de que la escuela es acusada de ser fuente de exclusión social, muchos la reconocen como la institución clave para la inclusión, por lo tanto hay que apostarle a su transformación. Esta es una tarea que nos corresponde no solo a los educadores, sino a todos aquellos interesados en el logro de una educación inclusiva. Así, se hace necesario promover alternativas educativas, sustentadas en enfoques inclusivos, que permitan garantizar el acceso a la educación de todos los niños y jóvenes con Necesidades Educativas Especiales.

La educación inclusiva se fundamenta en el reconocimiento de los Derechos Humanos, la equiparación de oportunidades, la autodeterminación, el respeto de la diversidad y el mejoramiento de la calidad de vida de todos los educandos sin importar su raza, sexo, condición física, cultura o creencia religiosa. Es decir, plantea una educación para todos; es ante todo una posición frente a los Derechos Humanos y, en este sentido, la escuela debe producir una respuesta educativa a las necesidades de todos los estudiantes y al principio de igualdad de oportunidades educativas, sin excluir a ninguna persona a causa de sus rasgos particulares o pertenencia a un grupo marginado o vulnerable.

Incluir significa ser parte de algo, formar parte del todo. La educación inclusiva enfatiza en cómo apoyar a los estudiantes para que desarrollen sus potencialidades dentro de una comunidad educativa, de tal manera que se sientan reconocidos como interlocutores válidos y alcancen el éxito académico con base en un aprendizaje significativo, centrado en el individuo. Así, para Moriña (2004, p. 15), la inclusión es: "[... ] una ideología social y educativa que defiende el derecho a la participación, sin exclusiones de ningún tipo, de todas las personas en sus comunidades sociales y escuelas".

En este sentido, ha cobrado fuerza la idea de que las instituciones educativas se constituyan en organizaciones que, además de promover el aprendizaje de todos los estudiantes, desarrollen mecanismos y estrategias orientados a eliminar las barreras que conducen a la discriminación y exclusión socioeducativa de determinadas personas. Desde esta perspectiva, se reconocen la diferencia y la diversidad como valores constitutivos de cualquier proceso educativo y como características inherentes al ser humano. La inclusión reconoce y celebra la diferencia, y crítica a la escuela porque la ha usado como forma de segregación. La inclusión concibe la diferencia como un valor positivo y enriquecedor para todos (Moriña, 2004, p. 17).

De otra parte, se considera la diversidad como un principio educativo y como una estrategia de cambio que debe 
orientar los procesos pedagógicos; donde las desigualdades se convierten en diferencias y no en motivación para la exclusión. Desde la educación inclusiva lo normal es la diversidad y por esta razón se distancia de la homogenización y normalización de los individuos. En una escuela inclusiva todos caben, todos son importantes.

En el marco de la inclusión, la diversidad se entiende como un término más amplio que considera las diferencias entre las personas y deja de lado cualquier tipo de jerarquización o categorización. No solo alude a diferencias entre alumnos, derivadas de las Necesidades Educativas Especiales, es un continuo donde tienen cabida las diferencias relativas a la pertenencia a minorías étnicas, a otras culturas, género, poblaciones marginales y a grupos en situaciones especificas (Ballard y Macdonald, 1998, Parrilla, 1998, citados por Moriña, 2004, p. 96). Así, se entiende que la inclusión no es un asunto solo de discapacidad, también incluye otros aspectos como raza, género, etnia, procedencia, etc.; es decir, se aplica a todas las situaciones de exclusión (Giangreco, 1997, citado por Moriña, 2004).

Avanzar hacia un proceso de educación inclusiva implica reestructurar culturas, políticas y prácticas en la escuela, para que éstas respondan a la diversidad de los estudiantes (Booth 2000, citado por Moriña, 2004). Parafraseando a Echeita (2006), podría afirmarse que la inclusión "[...] es un proceso que afecta tanto a la comunidad, en su más amplío sentido, como a los centros escolares con los que aquella cuenta [...] es un proceso con implicaciones en su cultura, en sus políticas y en sus prácticas de aula"; en otras palabras, es un proceso de carácter sistémico que impacta a toda la estructura de la institución e implica una transformación de la misma. Pero cambiar la institución educativa requiere detectar y tratar de eliminar las barreras para el aprendizaje y la participación existentes en todos los ámbitos de la acción educativa.

Es importante destacar que la educación inclusiva se puede considerar como una filosofía y práctica educativa emergente que pretende mejorar el acceso a un aprendizaje de calidad, en clases ordinarias para todos los estudiantes, a través de contextos de aprendizaje inclusivo desarrollados desde el marco de un currículo común. Bajo estos parámetros, la idea de avanzar hacia la construcción de una propuesta de educación inclusiva implica los siguientes retos para las instituciones: volver a pensar el currículo; repensar la diversidad de manera amplia; reestructurar la cultura y la organización de la institución y reconstruir la organización del aula (Moriña, 2006, pp. 33-34).

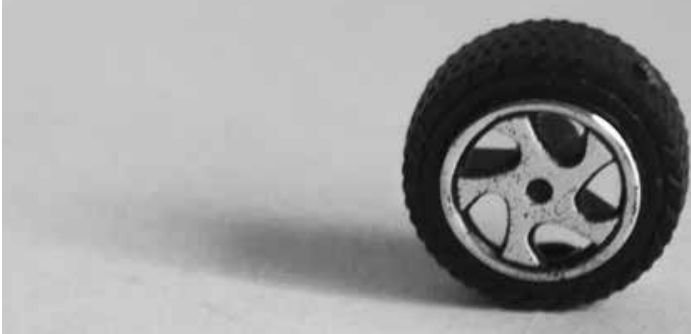

Según Muñoz (2006), la inclusión educativa es una búsqueda permanente de alternativas para responder a la diversidad. Conlleva aprender a vivir y a aceptar la diferencia como una oportunidad de nuevos aprendizajes tanto de niños como de adultos. Ello implica generar una serie de transformaciones en el sistema educativo y en la cultura que circula y que tiene lugar en el ámbito educativo. Requiere de una actitud flexible en la que cada ciudadano pueda y quiera construir y experienciar una sociedad abierta e inclusiva, que reconozca y respete los Derechos Humanos.

A modo de conclusión, es necesario reconocer que en las últimas décadas, en Colombia se han dado avances significativos en torno a la inclusión social y educativa de las personas en situación de discapacidad. Sin embargo, aún persisten en el ámbito escolar prácticas de exclusión y/o discriminación que vulneran los derechos de esta población y que la mantienen en condición de marginalidad y de desventaja.

En nuestro país, la propuesta de educación inclusiva ha conducido a que exista una importante diversidad de población en las instituciones educativas, dado que acogen no solo escolares en situación de discapacidad, sino, en aras de la inclusión, a otras poblaciones en riesgo social, tales como niños y jóvenes víctimas del conflicto, población extraedad y otros grupos que no se ajustan a la norma y que requieren de una atención educativa que responda a sus necesidades educativas específicas. Sin 
embargo, las instituciones educativas no siempre cuentan con la infraestructura y los recursos para reconocer esa diversidad y convertirla en una oportunidad pedagógica que garantice el pleno ejercicio del derecho a la educación de estas poblaciones.

Desafortunadamente en el ámbito educativo aún prevalecen propuestas educativas que se fundamentan en los parámetros de la homogeneidad y de la normalización de la población escolar, estos requieren de reflexiones y transformaciones profundas en su cultura institucional, sus prácticas educativas y su organización pedagógica y administrativa, para atender con pertinencia la diferencia de los estudiantes y lograr su inclusión social y educativa.

En tal sentido, se hace indispensable generar espacios permanentes de reflexión y discusión en torno a la educación desde la diferencia, con la perspectiva de conocer las concepciones y posturas de la comunidad educativa sobre el tema y de identificar alternativas y estrategias que favorezcan la transición de la integración educativa hacia la educación inclusiva, tal y como está estipulado en la actual política educativa que rige en nuestro país.

La educación inclusiva posee tanto un sentido educativo como uno social, rechazando toda forma de exclusión y discriminación que entorpezca el derecho de todos a la educación (Fernández, 2003). En este camino, la finalidad fundamental de la educación es promover el desarrollo de una serie de capacidades y la apropiación de determinados contenidos culturales necesarios para que los estudiantes puedan participar e integrarse en su medio sociocultural.

Para hacer realidad este fin, la escuela necesita proporcionar sus respuestas educativas de tal modo que garantice una cultura común a todos, pero que no discrimine, considerando la oportunidad y el respeto a las características y necesidades individuales de cada estudiante (Blanco, 1999). En este sentido, Booth y Ainscow (2002) afirman que existe una relación armónica entre las culturas, las políticas y las prácticas de la escuela. Esto nos fuerza a abordar dichas dimensiones de forma integrada, simultánea y coherente, a la hora de poner en marcha un proceso de cambio hacia una mayor inclusión.

Alcanzar procesos formativos que reconozcan y valoren las diferencias de los educandos y promuevan el diálogo entre lo diverso y lo diferente desde una perspectiva de los Derechos $\mathrm{Hu}-$ manos, se constituye en el principal desafío del sistema educativo, sobre todo cuando se trata de la formación inicial de docentes.

\section{Algunas reflexiones sobre la formación de docentes}

Formar docentes que lideren y asuman la educación inclusiva como una alternativa de re-conceptualización de la educación especial, requiere asumir propuestas de formación flexibles, que privilegien la participación y reconozcan la importancia del reconocimiento del otro (en su diversidad y su diferencia) y de la cultura, como elementos esenciales para el desarrollo de nuestros estudiantes.

En esta dirección, se considera necesario asumir una perspectiva educativa que privilegie la formación de un docente capaz de responder a las exigencias del contexto educativo y de avanzar hacia la reconstrucción y re-significación de su labor pedagógica. En tal sentido, consideramos que la perspectiva de reconstrucción social, planteada por Ángel Pérez (1994) ${ }^{3}$ se constituye en uno de los caminos posibles para abordar la formación de docentes.

La perspectiva de reconstrucción social concibe la enseñanza como una actividad crítica, como una práctica social, y al docente como un profesional autónomo que investiga y reflexiona críticamente sobre su práctica cotidiana; todo desde la perspectiva de transformar la realidad, de modo que su actuación reflexiva facilite el desarrollo autónomo de quienes participan en el proceso educativo. Así, se resalta la importancia de la reflexión, la investigación y la práctica como ejes fundamentales para configurar el quehacer del maestro, reconociendo la incidencia e importancia del contexto en el desarrollo del proceso pedagógico.

"Dentro de esta amplia perspectiva es necesario considerar, desde aquellos autores que se manifiestan abiertamente defensores de trabajar y desarrollar en la escuela y en el aula una propuesta ética concreta de justicia, igualdad y emancipación social y en los procesos de enseñanza y en los programas de formación de profesores/ as (Giroux, Smith, Zeichner, Apple, Kemmis; citados por Pérez, 1995), hasta aquellos otros que, desde posiciones más liberales, defienden la coherencia ética entre los principios, intencionalidades y procedimientos educativos democráticos, sin especificar de antemano un modelo concreto de sociedad (Stenhouse, Elliott, MacDonald; citados por Pérez, 1995)".

En el marco de esta corriente de pensamiento podrían ubicarse tendencias teóricas como la pedagogía crítico-social, la

3 Cabe aclarar que Ángel Pérez analiza y caracteriza a profundidad diferentes perspectivas de formación docente, dentro de las cuales menciona la perspectiva académica, la perspectiva técnica, la perspectiva práctica y la perspectiva de reconstrucción social. En este documento se retoma solo una de estas perspectivas, por considerar que se constituye en una alternativa posible para orientar la formación de educadores. 
pedagogía hermenéutico-participativa y el enfoque de construcción de conocimiento. Según Cristina Davini (1995, pp. 46-47) la pedagogía crítico-social se centra en:

"[...] la recuperación de los contenidos significativos en la enseñanza -dentro de un enfoque de crítica social e histórica- como instrumentos para la transformación social [...] el docente es visto como un mediador entre el material formativo (materias) y los alumnos, contextualizando críticamente los contenidos, las prácticas sociales y la enseñanza”.

Refiriéndose a la incidencia de la pedagogía crítica, la autora concluye que: "el impacto más fuerte [de esta tendencia] ha sido destacar la incompetencia de la escuela (y por ende, de los docentes) para lograr resultados de aprendizaje". A la vez, continuando con su análisis, Davini expresa que la pedagogía hermenéutico-participativa centra su atención en:

"[...] la modificación de las relaciones de poder en la escuela y en el aula, tanto en la revisión crítica de la organización institucional escolar, como en los rituales de la clase, las formas y las condiciones de trabajo, los dogmatismos y la estructura internalizada en los docentes como producto de toda una historia de formación [...] se busca que el docente revise críticamente las relaciones sociales en la práctica escolar, el verticalismo, la pasividad, las formas latentes de discriminación. Lo esencial sería modificar las prácticas, de modo que los docentes aprendan a pensar por su propia cuenta como camino a que formen, a su vez, sujetos pensantes, libres y solidarios".

Estas tendencias representan formas de resistencia a las maneras tradicionales de concebir el maestro y la escuela, y podrían calificarse como propuestas emancipadoras que el pensamiento pedagógico contemporáneo ha intentado consolidar para construir una nueva escuela, y para reivindicar el papel del maestro, en la democratización social y cultural de la enseñanza. Esta perspectiva de formación involucra una mirada del educando como un sujeto constructor, un sujeto de derechos, un sujeto político que está en la capacidad de participar activamente y de generar conocimientos y prácticas que conduzcan a transformaciones; es decir, concibe al docente en formación como transformador activo del conocimiento y como constructor de esquemas conceptuales alternativos.

Bajo esta figura, los criterios de formación tendrían en cuenta los siguientes aspectos como fundamentales:

- Generar acciones que apunten al análisis crítico del propio quehacer pedagógico y a la reflexión sobre diversos ambientes de socialización donde el proceso educativo tiene lugar.

- Profundizar en temas de interés del estudiante, los cuales surjan de las angustias e incertidumbres que afectan su proceso de formación y sus primeros contactos con la realidad educativa.

- Alcanzar una mayor comprensión de la labor como educador, desde actividades que involucren la observación y análisis de las propias acciones, la sistematización de la experiencia, la elaboración conceptual y la confrontación teoría-práctica; todos estos aspectos que fortalecen una actitud crítica y propositiva frente al quehacer cotidiano.

- Propiciar la participación y el análisis crítico de la realidad.

En esta misma línea, Zeichner (1990, citado por Pérez, 2009) argumenta que los objetivos de los programas de formación de docentes son: "Preparar profesores que tengan perspectivas críticas sobre las relaciones entre la escuela y las desigualdades sociales, y un compromiso moral para contribuir a la corrección de tales desigualdades mediante las actividades cotidianas en el aula y en la escuela" (p. 32). En los programas de formación de profesores, dentro de este enfoque, se presentan tres aspectos fundamentales:

- La adquisición por parte del docente de un bagaje cultural de clara orientación política y social. En esta perspectiva el lenguaje, la historia, la política y la cultura son considerados el eje central de los contenidos de una parte del currículo de formación.

- El desarrollo de capacidades de reflexión crítica sobre la práctica, para desenmascarar los influjos ocultos de la ideología dominante en la práctica diaria del aula, en el currículo, en la vida de la escuela y en los sistemas de evaluación.

- El desarrollo de las actitudes que requiere el compromiso político del docente como intelectual transformador del aula, la escuela y el contexto social. Es decir, actitudes de búsqueda, de experimentación, de crítica de interés, de trabajo solidario, de generosidad, iniciativa y colaboración.

Finalmente, cabe mencionar que la responsabilidad social y el reto de las facultades de educación está en revisar y ajustar sus programas de formación inicial de maestros, a las demandas y peculiaridades que exige una educación inclusiva que reconoce y atiende la diversidad y la diferencia en los procesos formativos. 


\section{Referencias}

Arnaiz, P. (2003). Educación inclusiva: una escuela para todos. España. Aljibe.

Blanco, R. (1999). Hacia una escuela para todos y con todos. Documento. Boletin Proyecto Principal de Educación en América Latina y el Caribe, No. 48. Santiago: UNESCO.

Booth, T., y Ainscow, M. (2002). Guía para la evaluación y mejora de la educación inclusiva. Madrid: Consorcio Universitario para la Educación Inclusiva.

Davini, M. C. (1995). La formación docente en cuestión: politica y pedagogía. Buenos Aires: Paidós.

Echeita, G. (2006). Educación para la inclusión o educación sin exclusiones. Madrid: Narcea.

Fernández, A. (2003). Educación inclusiva: enseñar y aprender entre la diversidad. Revista Digital Umbral 2000, 13. Obtenido el 10 de diciembre de 2013, desde http:/ /www.inclusioneducativa.org/content/ documents/Generalidades.pdf

García Pastor. (1986). Catálogo legislativo sobre Educación Especial en España (1900-1936).Sevilla: Servicio de Publicaciones Universitarias.

García Pastor. (1993). Una escuela común para niños diferentes. La integración escolar. Barcelona: EU.
Garrido, J. (1993). Adaptaciones curriculares. Colección educación especial y dificultades de aprendizaje. Madrid: Editorial CEPE.

Muñoz, V. (2006). Aplicación de la resolución 60/251 de la Asamblea General, titulada Consejo de Derechos Humanos, el derecho a la educación de las personas con discapacidades. Informe del relator especial sobre el derecho a la educación. Consejo de Derechos Humanos, cuarto período de sesiones, tema 2. New York: Organización de la Naciones Unidas (ONU).

Pérez, A. I. (1994). La función y formación del profesor/a en la enseñanza para la comprensión, diferentes perspectivas. En Sacristán, J. G., y Pérez, A. Comprender y transformar la enseñanza (398-499). Madrid: Morata.

Pérez, A. (2009). Las funciones sociales de la escuela: de la reproducción a la reconstrucción crítica del conocimiento y la experiencia. Consejo Latinoamericano de Ciencias Sociales (CLACSO). Argentina. FLAPE. Obtenido el 10 de diciembre de 2013, desde: http:// biblioteca.clacso.edu.ar

Riddel, S. (1998). Teorizar sobre las necesidades educativas especiales en un clima político cambiante. En Barton, L. (Ed.). Discapacidady sociedad (99-123). Madrid: Morata 